\title{
Literacy Globalization and the Demand for Cultural Change Policy
}

\author{
Mehraban Hadi Peykani ${ }^{1} \&$ Hadiyeh Tanhaie $\operatorname{Rad}^{1}$ \\ ${ }^{1}$ Isfahan (Khorasgan) Branch, Islamic Azad University, Isfahan, Iran \\ Correspondence: Mehraban Hadi Peykani, Isfahan (Khorasgan) Branch, Islamic Azad University, Isfahan, Iran. \\ E-mail: paykani2323@gmail.com
}

Received: March 10, 2016

doi:10.5539/ies.v9n11p82

\author{
Accepted: April 15, $2016 \quad$ Online Published: October 26, 2016 \\ URL: http://dx.doi.org/10.5539/ies.v9n11p82
}

\begin{abstract}
Rapid change has faced, information technology and communications world in the last two decades of the new type of illiteracy, failure to comply with the growth of the doctrine of technology on the one hand and lack of attention to retraining and learning. Traditional methods, educational structures, policies and governing policies and implementations objectives governing this issue as a cultural phenomenon, no longer massive volume of demand for education is not responsive and necessary than of the government is faced with this problem, how can the different sectors of society with the transformation of the educational need.

It is important that policies that literacy is part of the culture of each country have formulated policies, which uses different parts of culture and cultural diversity of the lands is written and the synergies necessary for the growth of literacy in society and move towards balanced development to occur and cultural of diseases caused by the global growth of literacy and lack of coordination with different cultures prevent these teachings.

This paper, based on the policy objectives of literacy, the dynamics of education, culture and politics and its effects, globalization, education and cultural policies of governments, review modeling literacy policy based on cultural diversity and change and increased participation of all society.
\end{abstract}

Keywords: literacy, cultural literacy policy, globalization

\section{Introduction}

You can start with a fundamental question that, what is the purpose of education in modern times?

Two last decades has witnessed fundamental changes in approaches to literacy (Maclachlan \& Cloonan, 2008, p. 124). Street (1995, p. 13) summarized the literacy flawed model "has been shown that non-cognitive skills are illiterate, live in the dark and backward and that literacy may independently lead to major effects in terms of cognitive skills and social development".

Alternative models of literacy as a ladder for people to climb it, and those who are illiterate are considered to be at the bottom of it does not think (Crowther et al., 2001, p. 2), this model instead for real social nature of literacy which made aware and sees language and literacy as social action and not as technical skills that must be learned during formal training, (Street, 2001: 17) Why that cannot be automated and non-value meanings to words, attributed either orally or in writing (Maclachlan \& Cloonan, 2008, p. 124).

Also found that different types and levels of literacy to be taught in schools Lo Bianco (2001) describes it as vaccination literacy, people cannot cope with the changing needs of an adult nature and equip. In addition, various schools and institutions literacy as powerful social institutions of the dominant social arrangements is legitimate and common activities (Maclachlan \& Cloonan, 2008, p. 125).

This speech studied the dynamics of change in the nature of literacy and its policies as a cultural phenomenon, with attention to the issue of globalization and how the role of conservative and strong educational institutions with flexible manufacturing culture and the necessary synergies in cultural literacy policies to suit the prevailing cultural diversity and the preservation of traditional culture.

\section{The Dynamics of Education, Culture and Politics}

Mayor believes, "for a community or an individual's nothing to enhance the skills and education of the human mind", is not essential. Literacy is the tool of education (UNESCO, 1972). Literacy opportunity to reflect on their status, discover new ones, and finally began to change, change in themselves and their culture. Sabaghyan 
(1978) issue of illiteracy and low literacy counts among the most important issues that now plague societies. It is rooted in history and culture, politics and economy of any society. (Hassan, 2010, p. 338)

According to the model Appadurai (1990) communities with the information society, knowledge-based society, post-industrial society, the regulatory community, the post-modern, post-national society, the international community faced, policy of engagement and dialogue are more global and universal and free access to information and knowledge, it is undeniable cultural policies (As cited in Crafts, 2003, pp. 297-301). Keep (2009) believes that the current challenges in the field by some of the skills that simple problems less seriously and left them become difficult and complicated.

Peters (2005) in that regard that as difficult and complex problem, the solution of problems that are not easily found. Human as increasingly complex changes in the world provides a lot of complexity in learning and literacy is consistent with the changes associated with, neglect of this two-way communication can be severe and cultural communities to delay the consequences.

\section{The Effect of Cultural Literacy Policymaking}

Cultural policy as a complex and multi-layered with multiple effects on different aspects of political, economic, technological and also by modern technology in logic and in the development of key tools associated with them. (Fazeli \& Qelich, 2013, pp. 13-14) Cultural events scattered and power relationships, on the other hand, no power, no single source, but also culture and technology related to its power in a given area is scattered. (Bennett, 1998, p. 6)

Culture policy action and power has emerged in practice and not in speech and language, in addition to the modern instrument, which is the same structure and organization of cultural creativity through new and regenerative role in the fabric of his culture and cause growth and development brings to society. (Fazeli $\&$ Qelich, 2013, p. 79) According to the guidelines listed above, there are structures such as literacy movement as a cultural technology, seems essential.

Welfare and prosperity of all communities in the development of the topics that are dealt with. In modern societies, welfare, is considered to be an important part of life with all aspects of human life. Traditionally, the income index is expressed, but prosperity, joy everyday life and the vision and the vision to build a better life in the future.

Legatum Institute from 2009 until now to evaluate the welfare of countries based on eight components, economy, entrepreneurship and opportunity, governance practices, education and health, safety and security, personal freedom and social capital ranked country. (Bidabadi, 2015, p. 10)

On the other hand, if the issue of literacy in our research-based analysis using the fishbone diagram these dimensions can be affected by it count, leading to improved literacy, peace, community development, education, gender equality, justice, health, energy, water and sanitation, ecosystem status, poverty eradication, economic growth, development sustainable, global communications, climate change, creating an integrated and flexible society, decent work and food security (Figure 1).

As a result Legatum index interacting with the literacy community and democracy, growth and security for the world brings. 


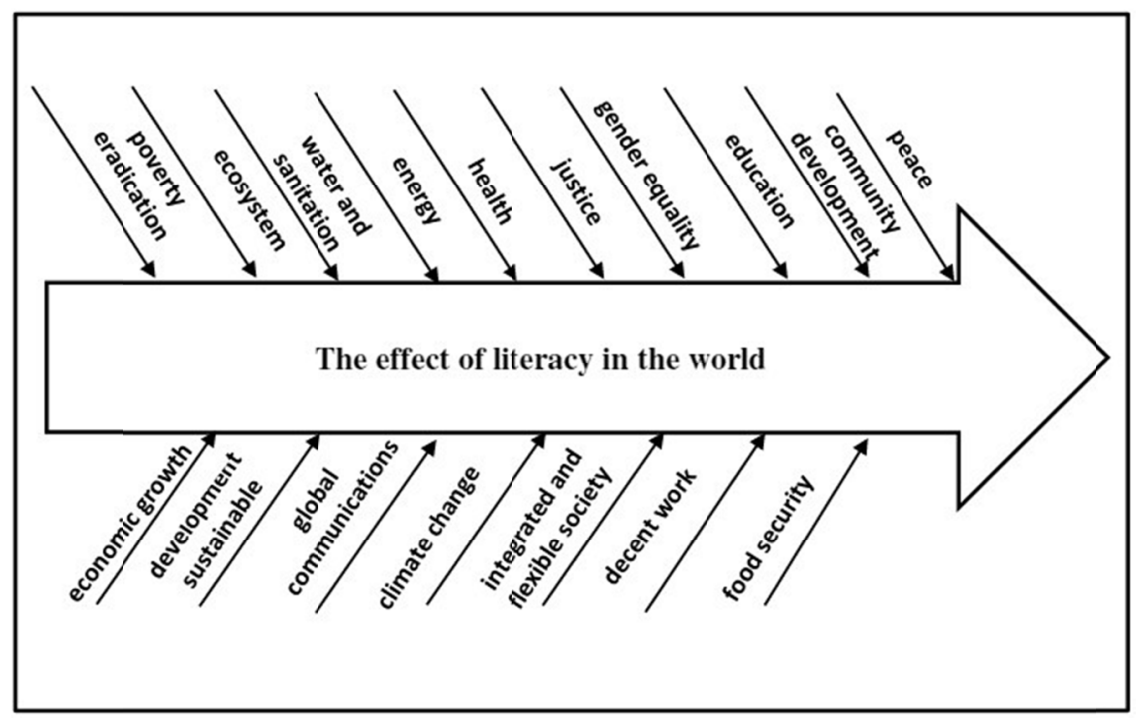

Figure 1. Fishbone diagram effect on world literacy

To build capacity in normal society considers three steps:

A. stage literacy and planning related to eradication in the country,

B. planning of the specialized skills needed in the field of civil society, including the economy, health care, etc.

C. solving economic, social, cultural and international understanding and insight into local events, regional, national, and global decision making in the face of it (Sereshteh, 1998, p. 53)

So, literacy is the most important cultural factor in building capacity in the community and want to look at the national, regional and world, up using cultural synergies created in this area to achieve a balanced growth and development.

Illiteracy or low literacy in Third World countries opens the way for colonial domination colonizers, so that countries feedstock culture fits with your objectives realistic plan to dominate and put at the disposal of these countries and finally took their campaign to the community, set literacy policies and policies governing the cultural element must be consistent with the needs of the cultural canvas of Works destructive flood relentless colonization is free. (Figure 2)

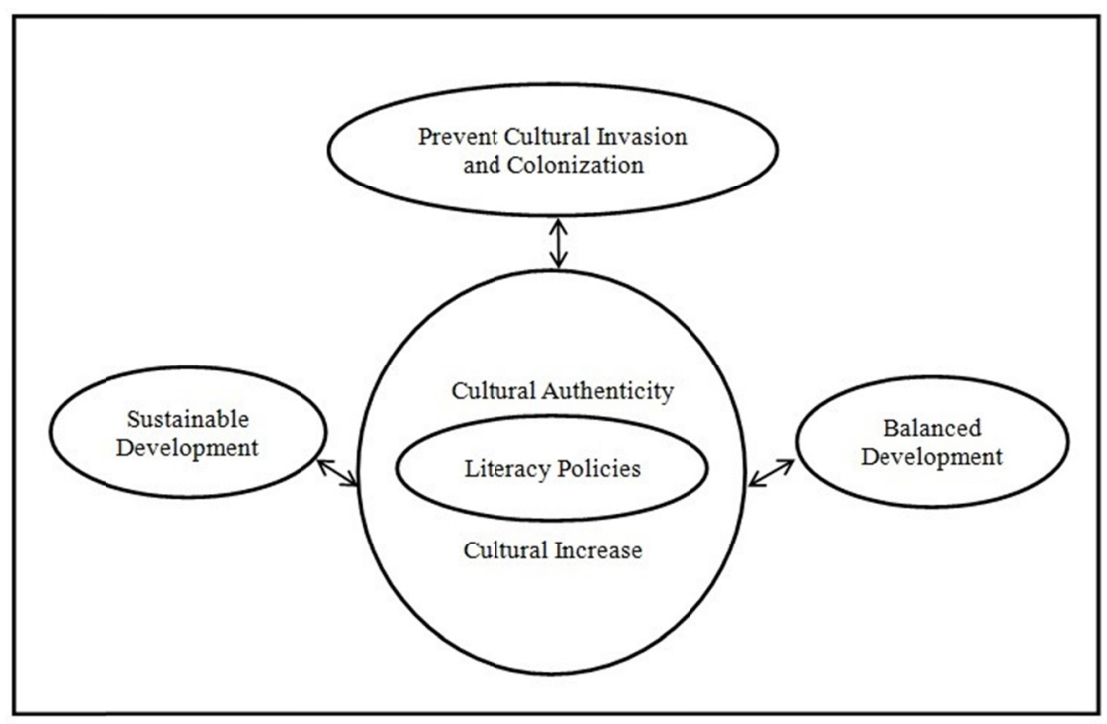

Figure 2. The effect of literacy on cultural policy-making communities 


\section{Globalization of Literacy and Culture of Government Policy}

UNESCO International Conference on Adult Education official international in 1949 relied on two things:

1) The need for social justice

2) The balance of international coordination in the Age of Communication and Information (Different from reference, 2008)

This is the opening statement for the International Literacy policies and this issue can no longer be a regional approach and depending on the issue and appropriate and balanced policy towards the countries should move together in this regard.

However, the globalization of culture describes three approaches:

1) Cultural Imperialism: The discourse in the 1960s was part of the Marxist critique of capitalist countries and advanced payment. This theory is based on the propositions and concepts of world-systems theory, argue that the global economic system dominated by developed countries and other countries, especially third world countries at the periphery of the system, little control over their economic and political development. (Tamilson, 2002: 39)

2) Circulation network: the argument based on this approach is that on the one hand the international media influence and control a wide variety of species cultures, but we are seeing ever increasing importance of diverse areas as manufacturing and trade sales culture, regions act as sub-networks that communicate with a global network of culture, and in this way, communication is established with other regions. (Crane, 2002: 7)

3) Reception Theory: This approach is based on the idea that the audience itself in many ways to interpret cultural texts and diversity and social characteristics of the recipient's interpretation and understanding of texts, features such as class, gender, race and age are all involved in a variety of interpretations. (Jahangardi, 2009: 97) As well as access and acceptance in this important and effective national culture. (Crane, 2005: 12)

In a general typology in response to the globalization of culture cultural policy three public discourses can be recognized from each other;

First discourse; prevention of the violation of indigenous and local achievements of other nations

Second discourse; resistance to global culture

Third discourse, expanding globalization markets (McGuigan, 2004: 36).

Ethnic and cultural diversity of the cultures using a country's land area and relying on cultural diversity and a variety of arts and customs and what tools to use in design and in execution of a policy objectives, especially the issue of literacy capacities to the actual potential, and in developing appropriate and balanced education both in content and in the amount and discover new and useful lessons in this regard that and the objectives of the prevention and protection of national culture Discourse discussed a land.

Analyze problems and correct understanding of community problems and build a political model according to the structures of society and avoiding any successful models in the target population, resistance necessary to combat global culture and its inappropriateness.

According to the theory is also important to accept that the access and adoption of national culture in the country will be strengthened to interpret and understand cultural texts (such as cultural texts can be educational structures and the issue of literacy and otherwise.) In line with national policies be accompanied by awareness and literacy with international standards, aboriginal culture and traditional values and culture on the one hand maintain the new doctrine took shape in accordance with the values of society and societies from the dangers of cultural transposition of new and global phenomenon teachings and kept confidential.

In the discourse of development and expansion of world markets to absorb an emphasis on world markets, foreign or non-native consumer attract visitors to show competitive advantages of a structure or a cultural phenomenon, hence, policy makers and their successful literacy can be used to provide such structures are consumers and established itself as a leader in the educational system in the world and two precious benefits, the move towards sustainable development and branding, cultural, literacy phenomenon of their own.

\section{Making or Implementation Model Literacy Policy}

In a comparative study, policy makers are looking for practical policy programs. (National Literacy Agency, 
2011, p. 13) Analysts transfer processes on the policies of borrowing and agree that policymakers should resist against these policies. Because it is only in the interest and effective policies on other countries and does not have the correct version.

They believe that the practice of these policies will guide us towards a transformation, a transformation that end, according to the context of a culture very different from the policy was implemented and not to a best practice, but it may be the worst way. (Steiner-Khamsi, 2010)

Policy makers should move towards personal knowledge of comparative studies and attempts to create political model, commensurate with the challenges and culture of a society and its actions rather than holding on for practical objectives utilize in policy development and literacy.

\section{Literacy Policymaking Based on Multicultural Groups}

Nowadays, companies to manage complex and dynamic environments on their present age groups. Now, a group of the solution to deal with the problems of external adaptation to a changing environment is complex and dynamic. Groups to work and to find successful solutions to the problems of external adaptation, we must find solutions to the problems of internal cohesion. Also, the groups to be effective when solving problems of external adaptation and internal integration, to create its own culture.

Over time, members of the group behaviors, values, beliefs and assumptions that may be more or less influenced by the national culture are welcome (Schneider \& Barsoux, 2014, pp. 307-308). This is while governments for policymaking on some issues, particularly the issue of literacy this capacity can be spontaneous and cultural groups in the area to take advantage necessary and through this, the cultural synergy of objectives and functions to create cultural policies.

The root cause of this type of policymaking is the development of cultural differences. In this type of policymaking, culture as an opportunity and a source of advantage counts. The expected benefit in this type of policymaking initiative and learning and communication channels covers all three strains. A major challenge and a major concern confusion and friction level differences in cultural encounters and cultural synergies.

Some of the benefits of implementing diversity policies include: aspects of marketing, the ability of governments to provide and meet the cultural preferences of local markets, in terms of education, ability to attract forces from different national backgrounds and also increase the country's elite Gives. In terms of costs, the cost of non-native managers to reduce loss.

From aspects of the problem, enjoying the variety of perspectives and providing a comprehensive, critical analysis, decision-making better. In terms of creativity, through a variety of views and for less emphasis on the need for harmony and equality, to strengthen creativity. In terms of system flexibility, the flexibility and tolerance and meet the various demands and increases dynamic environments.

From potential benefits of cross-cultural interaction lies in the fact that we must respect the views of others and to respect them and be prepared that we value them, rather than trying all think the same way. (Schneider \& Barroso, 2014, pp. 346-350) Taking into account cultural differences, the basic rule to democracy, to use all capacities in the field of literacy and ultimately achieve sustainable development have been considered.

\section{Using Society Participation in Policy Literacy}

Culture, intertwined totality of knowledge, religion, art, law, morals, customs and any other capabilities and habits which man acquires as a member of society (Ashouri, 2010, p. 39). Edgar Shayon culture as a set of basic principles and common solutions to global environmental problems of external adaptation (how to survive) and internal consistency (How to stay side) the assumptions and basic principles evolved over time and from one generation to another is defining (As cited in Schneider \& Barsoux, 2014, p. 31).

According to Shayon, culture:

First, the model and pattern,

Second, the assumptions explore, create, or provided by a specific group,

Third, to address and resolve compatibility issues are raised environmental and internal cohesion,

Fourth, as a guide to think, imagine and feel is given to staff members.

Shayon culture has three levels or three layers know that and discovering there any special procedures;

The first level, synthetic (behaviors, manners such as greetings, dress, artifacts, art, architecture, symbols and rituals, etc.) that includes all aspects of culture that is visible. 
The second level, beliefs and values (truth and reality, about the right way to live out and ideals of individual preferences) contains the dos and don'ts that can be identified through interviews and surveys.

The third level of basic assumptions (including with respect to the deeply held beliefs and systems of meaning, the nature of human activity, the nature of reality, a view which related to compliance with environmental and human nature, relationships with people, space, time and language related the internal cohesion of human groups.) that is the deepest level of culture and from way of inference and interpretation can be identified. (Schneider \& Barroso, 2014, pp. 35-70)

Using that model can be questioned two processes at the same time for society to change and prosecution efforts and encourage them to move to literacy compliance with environmental changes and maintain internal cohesion and the fight against cultural invasion adopted, governments used to provide artificial structures and technologies and facilities put at the disposal of society.

On the other hand, taking into account cultural differences in different clusters using education and culture through the third layer, change people's deeply held beliefs about the definition of literacy in the world, change and new values according to different cultural groups in the community offer genuine value, this process occurs in three forms in society.

On the one hand for spontaneous campaign to combat illiteracy and associations relevant to global change, by informing the public takes shape and on the other hand the new regulation come up with new structures balance between global change, structure and established new standards literacy, with the help of the groups or governments and voice popular, grassroots and media campaigns to change and grow they acquire literacy in the community.

In many countries, participation in adult literacy policy is the main criterion of success, participation is based on the belief that literacy focus on the whole range of positive benefits for society as well (Carpentieri \&Vorhaus, 2010). This is especially true with the participation of disadvantaged groups in terms of infrastructure and voice done on minority cultural groups.

In some countries, including Ireland and the United Kingdom, the mainstream media campaign by providing free services, effectively raising awareness of adult literacy issues and to encourage and attract them have been successful (Bynner \& Parsons, 2006).

Sweden, under the scheme of adult education in order to overcome structural barriers and cultural boundaries among underserved areas, to expand the educational infrastructure, Swedish policy makers insights on the effects of participation with the assumption that if the supply of learning opportunities increase, participation also increased the target groups and social-democratic attitudes, including adult education as a public investment (Veeman, 2004).

The relatively high level of participation in adult education in Scandinavian countries, primarily related to the high level of public support for adult education and targeting disadvantaged groups and social justice in this country and ultimately designated as the Nordic model (Tuijnman, 2003, p. 327). This model is a learner-centered concept of sustainability and its success has been founded on this issue, what is the mechanism that learners face in various stages of lifelong education. (Carpentieri, 2008)

Literacy policy can be divided into two main parts; policy in objectives, goals, strategies, guidelines and tools created by policy makers and policy implementation to improve literacy skills, this dimension to describes how the policies in the real world and the fact that policies Why, when and how responsive they are (National Agency for Literacy, 2011, p. 12).

In Islamic Iran Country, continuous efforts to develop scientific, cultural and technical community and the spread of literacy and education component of cultural policy principles that guide the authorities, managers and planners and brokers are cultural activities and training. (Fazeli \& Qelich, 2012, pp. 151-150)

Islamic teachings on personal knowledge of the underlying assumptions and stress, but it is important that policy coordination in two sector have objectives and try to be, policies as cultural slogan on the package did not fit and be used for practical measures. Finally policies that interact and participate in society with respect for cultural diversity, minority groups consider, appropriate and up to date scientific and technical infrastructure to be used in the performance of sustainability and more.

\section{Conclusion}

Globalization flows of capital, goods, services, technology, information and communication increasingly has weakened government control over time and space. Multiple identities, took control of the government through 
the deployment of tradition and history that made possible the construction of national identity was known to the challenge. During the globalization of culture, we are faced with unprecedented themes and issues that are cultural in nature.

A new study of literacy as a common issue in which national governments on the one hand, and the other by the globalization culture through its various communication tools, meaning they seek to challenge and each is trying to offer their cultural values. Government, depending on the nature of the capacity and power to politicians and their cultural policies, they also use legitimate monopoly of power for formulating and imposing policies in their possession and the reasons and objectives are sufficient to make such an important feature.

Cultural policy in the broad sense that such policies could be part of public policy in the narrow sense and in a broad sense is examined. Logical and rational position in the face of cultural globalization is taking into account the interests and national security. What is referred to as cultural policy and governance at various levels, in the most democratic governments and political systems to control the regularity of the influence of alien cultures across national boundaries.

The world in the last two decades of failure to comply with the new phenomenon of illiteracy education with global change on the one hand and as a matter of looking at the phenomenon of continuous training throughout life people face, this situation in developing countries and countries with enormous natural resources, major investments in human capital, building the knowledge based society made unnecessary is more severe.

In these countries, economies based on exports of natural resources such as oil rents have stabilized; these specifications may very wealthy country, but no post-industrial economy that occupational diversity, social complexity, spread knowledge and human autonomy with the promise of a democracy to have not brought with them (Inglehart \& Welzel, 2010, p. 78).

It should be noted in such countries a new study of literacy and policies related to the phenomenon and as new and more flexible motion control with forward, futures, taking into account cultural differences in order to preserve the internal coherence of external adaptation to global change and land use policy Aboriginal models with two simultaneous effect, use of modern means of education, awareness and education campaigns using media literacy and multicultural groups affected by basic assumptions and participation of all communities in accordance with their group culture toward cultural synergies and obtain sustainable development on the one hand and to prevent cultural invasion drove the phenomenon of the outer structure and non-Aboriginal literacy, land secured, has finally achieved the promise of democracy in society.

\section{References}

Ashouri, D. (2010). The definition and concept of culture. Tehran.

Bennett, T. (1998). Culture-A Reformer s Science. London, Thousand Oaks and New Delhi: Sage.

Bidabadi, H. (2015). Legatum among the 142 countries assessed. Journal of Futures Studies, 7, 10-11.

Bynner, J., \& Parsons, S. (2006). New Light on Literacy and Numeracy. London: NRDC.

Carpentieri, J. D. (2008). Learning for and in the workplace. London: NRDC.

Carpentieri, J., \& Vorhaus, J. (2010). "The social value of further education in adult learning”, in Colleges 2020. London: IPPR.

Crafts, A. (2003). Concepts of national cinema. Organon Journal, 23.

Crane, D. (2002). Culture and Golabalization. Theoretical model and emerging trend. In D. Crane (Ed.), Culture and Golabalization (pp. 1-28). UK, Routledge.

Crowther, J. et al. (2001). Powerful Literacies. Leicester: NIACE.

Ebrahimzadeh, H. (2008). Adult Education. Tehran: PNU.

Fazeli, N., \& Qelich, M. (2012). A New Approach to cultural policy. Published TISA.

Hassan, B. (2010). Factors affecting cultural preservation in the Islamic Republic of Iran. Strategy Journal, 20(58), 335-366.

Inglehart, R., \& Wezel, Ch. (2010). Modernization, and Democracy. Translation Ahmadi, Tehran: Kavir.

Jahangardi, M. (2009). Stimulating consumption Persian-language satellite channels, cultural studies (Graduate thesis, Supervisor: Mahmoud Shahabi, Tehran, Allameh Tabatabai University Faculty of Social Sciences).

Keep, E. (2009). Initial submission on adult learning in the workplace-explaining current patterns and their 
outcomes. Leicester: NIACE.

Lo Bianco, J. (2001). Language and Literacy Policy in Scotland. Stirling: CILT, Universityof Stirling.

Maclachlan, K., \& Cloonan, M. (2008). Three dimensional change? Therelationship between theory, policy and adults' understanding of literacies, Research in Post-Compulsory Education, 8(1), 123-136. http://dx.doi.org/10.1080/13596740300200144

McGuigan J, (2013). Rethink the cultural policy. Morteza Fazeli and Nemat Qelich, Tehran, Imam Sadegh University.

McGuigan, J. (2004). Rethinkiing cultural policy. UK, Open university press.

Natonal Adult Literacy Agency. (2011). A Literature Review of International Adult Literacy Policies.

Peters, G. B. (2005). The Problem of Policy Problems. Journal of Comparative Policy Analysis: Research and Practice, 7(4), 349-370. http://dx.doi.org/10.1080/13876980500319204

Sabaghyan, Z. (1978). Literacy lessons. Tehran: School Publishing.

Schneider, S. C., \& Barsoux, J. L. (2014). Management across cultures. Seyed Mohammad Arabs and others, Tehran: Cultural Research Bureau, First Published.

Sereshteh, M. (1998). The main objectives of cultural planning. Ministry of Culture and Islamic Guidance, Tehran.

Steiner-Khamsi, G. (2010). The politics and economic is of comparison: Presidential address. Comparative Education Review, 54(3). http://dx.doi.org/10.1086/653047

Street, B. (1995). Social Literacies. Harlow: Longman.

Street, B. (2001). Contexts for Literacy Work. In J. Crowther et al. (Eds.), Powerful Literacies. Leicester: NIACE.

Tamilson, J. (2001). Globalization and culture (Translation Mohsen Hakimi). The Cultural Research Bureau.

Tuijnman, A. C. (2003). "A Nordic Model" of Adult Education: What Might Be Its Defining Parameters? International Journal of Educational Research, 39(3), 9. http://dx.doi.org/10.1016/j.ijer.2004.04.008

UNESCO. (1972). Achievements in literacy issues and processes (Translation M. Torabi). Tehran: International Institute of Adult Education methods.

Veeman, M. N. (2004). Adult learning in Canada and Sweden: a comparative study of four sites. University of Saskatchewan.

\section{Copyrights}

Copyright for this article is retained by the author(s), with first publication rights granted to the journal.

This is an open-access article distributed under the terms and conditions of the Creative Commons Attribution license (http://creativecommons.org/licenses/by/4.0/). 